\title{
Analysis of the Magnetocaloric Effect in Powder Samples Obtained by Ball Milling
}

\author{
J.S. BLÁZQUEZ, J.J. IPUS, L.M. MORENO-RAMÍREZ, J.M. BORREGO, \\ S. LOZANO-PÉREZ, V. FRANCO, C.F. CONDE, and A. CONDE
}

\begin{abstract}
Since the discovery of the giant magnetocaloric effect (MCE) close to room temperature in FeRh and particularly in $\mathrm{Gd}_{5} \mathrm{Si}_{2} \mathrm{Ge}_{2}$ compounds, the study of this phenomenon has experienced an exponential growth. Among the different techniques used to produce magnetocaloric materials, ball milling has been shown as a very versatile one and presents several advantages over other preparation techniques (e.g., easy scale-up to industrial production). Although a general decrease of the peak value of the magnetic entropy change is observed for milled samples, it can be compensated by the large broadening of the MCE peak, leading to an increase of the refrigeration capacity. In this short review, several aspects inherent to powder samples affecting MCE will be discussed, such as the relevant effect of the demagnetizing field, the possible multiphase character, and the presence of Curie temperature distributions. In mechanically alloyed samples, the two latter factors are typically affected by the degree of integration of the different starting constituents.
\end{abstract}

DOI: $10.1007 / \mathrm{s} 40553-015-0050-0$

(C) ASM International (ASM) and The Minerals, Metals \& Materials Society (TMS) 2015

\section{INTRODUCTION}

THE magnetocaloric effect (MCE) is described as the reversible adiabatic change of the temperature, $\Delta T_{\mathrm{ad}}$, or as the reversible isothermal change of the magnetic entropy, $\Delta S_{\mathrm{M}}$, of a system due to a change in the applied magnetic field. Both magnitudes are related to the temperature change of the magnetization through the Maxwell relation.

$$
\begin{gathered}
\Delta T_{\mathrm{ad}}=-\mu_{0} \int_{H_{\min }}^{H_{\max }} \frac{T}{c_{\mathrm{p}}}\left(\frac{\partial M}{\partial T}\right)_{H} \mathrm{~d} H, \\
\Delta S_{\mathrm{M}}=\mu_{0} \int_{H_{\min }}^{H_{\max }}\left(\frac{\partial M}{\partial T}\right)_{H} \mathrm{~d} H,
\end{gathered}
$$

where $\mu_{0}$ is the magnetic permeability of vacuum, $T$ is the temperature, $c_{\mathrm{p}}$ is the specific heat, $M$ is the magnetization, and $H$ is the magnetic field which changes between a minimum, $H_{\min }$, and a maximum, $H_{\max }$, values. In most cases, $H_{\min }=0$ and in the following this case will be considered.

J.S. BLÁZQUEZ and J.M. BORREGO, Associate Professors, J.J. IPUS, Postdoctoral Contract, L.M. MORENO-RAMÍREZ, Ph.D. Student (Contract), V. FRANCO, C.F. CONDE, and A. CONDE, Full Professors, are with the Dpto. Física de la Materia Condensada, ICMSE-CSIC, Universidad de Sevilla, P.O. Box 1065, 41080 Seville, Spain. Contact e-mail: jsebas@us.es S. LOZANO-PÉREZ, Associate Professor, is with the University of Oxford, Parks Road, Oxford OX1 $\mathrm{P} 3 \mathrm{H}, \mathrm{UK}$

Manuscript submitted February 6, 2015.

Article published online May 12, 2015
The rising of scientific interest in $\mathrm{MCE}$ at room temperature coincides with the discovery of the giant magnetocaloric effect close to room temperature in $\mathrm{Gd}_{5} \mathrm{Si}_{2} \mathrm{Ge}_{2}$ compound by Gschneidner Jr. and Pechars$\mathrm{ky} \cdot{ }^{[1]}$ This is due to the near-future perspective for its application in environmentally friendly room temperature magnetic refrigeration technology. As it is observed in Eqs. [1] and [2], a large MCE requires a large temperature dependence of magnetization and thus implies a change in magnetization as abrupt as possible. Magnetic refrigeration at ultralow temperatures was known since the experiments of Giauque (1949 Nobel Prize) and MacDougall ${ }^{[2]}$ to attain temperatures below $1 \mathrm{~K}$ using paramagnetic salts (where susceptibility diverges as $T$ approaches $0 \mathrm{~K}$ ). However, for room temperature MCE, the presence of a phase transition is required to enhance the temperature dependence of the magnetization. Therefore, the different materials can be classified in terms of the character of such transition as first-order phase transition (FOPT) or second-order phase transition (SOPT) materials. A FOPT generally leads to larger MCE responses at the temperature of transition, although hysteresis phenomena can be present. Among the families of materials in this category, the most significant are $\mathrm{Gd}_{5}(\mathrm{Si}, \mathrm{Ge})_{4}{ }^{[1,3]}$ $\mathrm{La}(\mathrm{Fe}, \mathrm{Si})_{13} \mathrm{H}_{\delta},{ }^{\left[{ }^{4]}\right.}$ Heusler alloys, ${ }^{[5]}$ and $\mathrm{MnAs} ;{ }^{[6]}$ other families can be found in Reference 7. On the other hand, for SOPT, Gd is the paradigmatic material, ${ }^{[8]}$ with a negligible hysteresis and no giant MCE. In this second category, amorphous alloys, due to its easy tunable parameters through compositional tailoring, have also been intensively studied in the last years. ${ }^{[9-11]}$ To characterize the MCE response, the refrigerant cooling power RCP is widely used as the product of the 
maximum absolute value of $\Delta S_{M}$ and the full width at half maximum of the $\Delta S_{\mathrm{M}}(T)$ curve. ${ }^{[7]}$

This work is divided into five sections. After this introduction, the second section briefly summarizes the different types of materials with interesting MCE response produced by ball milling. The following sections will focus on the description of several aspects affecting MCE response and of particular interest in the case of ball-milled powders. The third section will describe the relevant effect of the demagnetizing field. This effect is not negligible except for thin films, ribbons, or needles, when its shortest length is perpendicular to the magnetic field. The effect of impurities and multiphase character of ball-milled samples will be discussed in the fourth section. In mechanically alloyed samples, this is typically affected by the degree of integration of the different starting constituents. The fifth section will be devoted to the presence of Curie temperature distributions in milled samples. In all cases, particular attention will be focused on the field dependence of the MCE response.

\section{RESULTS ON MCE OF BALL-MILLED SAMPLES}

Ball milling (BM) technique has been shown as a very versatile technique to prepare supersaturated solid solutions and other metastable systems, including amorphous alloys ${ }^{[12]}$ for a larger compositional range than that obtained by rapid quenching techniques. The main advantages of ball milling techniques are the diversity of materials that can be treated independently of their different melting points (although ductile and brittle materials are incorporated in a different way) and an easy scale-up of the technique. On the other hand, a main factor that has to be taken into account in this type of samples is the presence of contamination from the milling media.

Concerning MCE results, ball milling has been used to study a wide variety of materials, including rare earth (RE) and transition metal (TM)-based systems. Among RE-based materials $\mathrm{Gd}_{5} \mathrm{Si}_{2} \mathrm{Ge}_{2},{ }^{[13,14]} \mathrm{La}(\mathrm{FeSi})_{13},{ }^{[15-18]}$ $\mathrm{RE}_{2} \mathrm{Fe}_{17}$ intermetallics, ${ }^{[19,20]}$ clathrates $\mathrm{Eu}_{8} \mathrm{Ga}_{16} \mathrm{Ge}_{30},{ }^{[21]}$ and amorphous alloys ${ }^{[13,14,22]}$ can be found. Among TM-based systems Heusler alloys ${ }^{[23-25]} \mathrm{MnAs},{ }^{[26-29]} \gamma-$ FeNi, ${ }^{[30-32]}$ and amorphous alloys ${ }^{[33-37]}$ can be found. A general difference found in $\mathrm{BM}$ samples regarding their MCE with respect to that of bulk counterparts is a decrease of the $\Delta S_{\mathrm{M}}$ peak but a temperature broadening of the MCE response, which can lead to an enhancement of the refrigerant cooling power. In particular cases, the presence of intermetallics with suitable Curie temperatures can lead to an enhancement of MCE. ${ }^{[35]}$ For Fe-based amorphous alloys obtained by rapid quenching, subsequent ball milling produces an increase in the metal-metal distance enhancing the magnetism of the system. ${ }^{[36]}$ However, extended milling can deteriorate the MCE signal when the phase responsible for it is destroyed, as it occurs for $\mathrm{Gd}_{5} \mathrm{Si}_{1.8} \mathrm{Ge}_{1.8} \mathrm{Sn}_{0.4}$ system, for which an amorphous phase is formed. ${ }^{[13]}$
The use of BM can be found in the literature as a single-step production technique (e.g., amorphous alloys). However, annealing can be necessary to produce the desired phase and then BM is used as a first step to prepare a well-mixed system (e.g., BM reduces the annealing time in $\mathrm{La}(\mathrm{Fe}, \mathrm{Si})_{13}$ alloys ${ }^{[15,16]}$ ) or as a final step in a reactive milling process (e.g., forming hydrides in $\left.\mathrm{La}(\mathrm{Fe}, \mathrm{Si})_{13} \mathrm{H}_{\delta}{ }^{[17,18]}\right)$. Some examples of the different MCE results achieved on ball-milled samples are summarized in Table I.

\section{EFFECT OF THE DEMAGNETIZING FIELD}

When characterizing the MCE of a system, some confusion can be found in the literature regarding the magnitude of the parameter $H$ that must be used in Eqs. [1] and [2]. This is particularly important for powder samples, for which there is no orientation to minimize the demagnetizing field effect. Two cases can be distinguished:

a) For the characterization of a material, independent of the geometry of the studied sample, $H$ must correspond to the internal field, $H=H^{\text {appl }}-N_{\mathrm{D}} M$, where $H^{\text {appl }}$ is the applied magnetic field and $N_{\mathrm{D}}$ is the demagnetizing factor. In order to supply $\Delta S_{M}$ data that could be reproduced in samples with different geometry but with the same microstructure and composition, it is needed to calculate Eqs. [1] and [2] for a fixed maximum internal field.

b) On the other hand, when the interest is focused on the response of a particular sample (e.g., a characteristic geometry to be used in a device), although the magnetization and its temperature derivative must correspond to the internal field, $H$, the maximum integration limit is not constant but depends on temperature through the magnetization. The constant parameter is the maximum applied magnetic field, $H_{\max }^{\mathrm{appl}}=H_{\max }+N_{\mathrm{D}} M\left(H_{\max }, T\right)$. For example, for a simulated material following Brillouin function and using the magnetic moment, density, and Curie temperature values of pure $\mathrm{Gd}$, case (a) leads to $\Delta S_{M}=-3.60 \mathrm{~J} \mathrm{~kg}^{-1} \mathrm{~K}^{-1}$ at $T_{\mathrm{C}}$ and $\mathrm{RCP}=108 \mathrm{~J} \mathrm{~kg}^{-1}$ for $H_{\max }=1 \mathrm{~T}$, whereas in case (b), a sphere $\left(N_{\mathrm{D}}=1 / 3\right)$ of the same material has $\Delta S_{\mathrm{M}}=-3.16 \mathrm{~J} \mathrm{~kg}^{-1} \mathrm{~K}^{-1}$ and $\mathrm{RCP}=73 \mathrm{~J} / \mathrm{kg}$ for a maximum $H^{\text {appl }}=1 \mathrm{~T}$ (which implies an internal field $H_{\max }=0.816 \mathrm{~T}$ at $T_{\mathrm{C}}$ ). Between the two cases described above, case (a) is more relevant in order to compare different results obtained under different experimental conditions.

Despite the importance of demagnetizing field for the correct characterization of the samples, the applied field is seldom corrected to the internal field. ${ }^{[37-44]}$ This correction can be done using $N_{\mathrm{D}}=1 / 3$ for loosely spherical powder samples or for spherical powder in a spherical pack, which is derived from the expression: ${ }^{[45]}$

$$
N_{\mathrm{D}}=\frac{1}{3}+f\left(N_{\mathrm{D}}^{\mathrm{pack}}-\frac{1}{3}\right) \text {, }
$$


Table I. Summary of Selected Works on MCE Where Ball Milling has been used for Sample Preparation

\begin{tabular}{|c|c|c|c|c|c|c|}
\hline Composition & Use of Ball Milling & Advantages & $H(\mathrm{~T})$ & $\begin{array}{c}\left|\Delta S_{\mathrm{M}}\right| \\
\left(\mathrm{J} \mathrm{kg}^{-1} \mathrm{~K}^{-1}\right)\end{array}$ & $T_{\text {peak }}(\mathrm{K})$ & References \\
\hline $\mathrm{Gd}_{5} \mathrm{Si}_{1.8} \mathrm{Ge}_{1.8} \mathrm{Sn}_{0.4}$ & $\begin{array}{l}\text { grain size reduction/ } \\
\text { amorphization }\end{array}$ & hysteresis reduction & 5 & 4.3 & 75 & [13] \\
\hline GdNiAl & & new phase & 5 & 8.9 & 36 & {$[22]$} \\
\hline $\mathrm{Gd}_{5} \mathrm{Si}_{2} \mathrm{Ge}_{2}$ & & broadening & 2 & 0.45 & 220 & [14] \\
\hline $\mathrm{Pr}_{2} \mathrm{Fe}_{17}$ & & & 5 & 4.5 & 295 & [20] \\
\hline $\mathrm{Eu}_{8} \mathrm{Ga}_{16} \mathrm{Ge}_{30}$ & & low $T$ enhancement & 5 & 10 & 5 & [21] \\
\hline $\mathrm{Ni}_{2.18} \mathrm{Mn}_{0.82} \mathrm{Ga}_{1}$ & one step (mechanical alloying) & $\begin{array}{l}\text { different melting points } \\
\text { of the constituents }\end{array}$ & 2 & 1.6 & 310 & [23] \\
\hline $\mathrm{Ni}_{47} \mathrm{Mn}_{40} \mathrm{Sn}_{13}$ & one step (mechanical alloying) & $\begin{array}{l}\text { different melting points } \\
\text { of the constituents }\end{array}$ & 2 & $4.3 / 2.3$ & $210 / 318$ & [24] \\
\hline $\mathrm{Mn}_{0.95} \mathrm{Cr}_{0.05} \mathrm{As}$ & intermediate step & Avoid volatilization of As & 5 & $6.3 / 5.3$ & $159 / 234$ & [29] \\
\hline $\mathrm{Mn}_{1-\mathrm{x}} \mathrm{Si}_{\mathrm{x}} \mathrm{As}$ & mechanical alloying & & 2 & 6.5 & 264 & [26] \\
\hline $\mathrm{Mn}_{1-\mathrm{x}} \mathrm{Al}_{\mathrm{x}} \mathrm{As}$ & & & 2 & 28.5 & 270 & {$[27]$} \\
\hline $\mathrm{MnAs}_{0.97} \mathrm{P}_{0.03}$ & & hysteresis reduction & 5 & $5.6 / 4.4$ & $208 / 253$ & [28] \\
\hline $\mathrm{Fe}_{75} \mathrm{Nb}_{10} \mathrm{~B}_{15}$ & & amorphization & 1 & 0.56 & 266 & [41] \\
\hline$\left(\mathrm{Fe}_{85} \mathrm{Co}_{15}\right)_{75} \mathrm{Nb}_{10} \mathrm{~B}_{15}$ & & & 1.5 & 0.85 & 450 & [34] \\
\hline $\mathrm{Co}_{62} \mathrm{Nb}_{6} \mathrm{Zr}_{2} \mathrm{~B}_{30}$ & & & 1.5 & 0.35 & 550 & {$[37]$} \\
\hline$\left(\mathrm{Fe}_{70} \mathrm{Ni}_{30}\right)_{89} \mathrm{Zr}_{7} \mathrm{~B}_{4}$ & & metastable phases & 0.5 & 0.18 & 342 & [30] \\
\hline $\mathrm{Fe}_{70} \mathrm{Ni}_{30}$ & & & 1.5 & 0.65 & 363 & [31] \\
\hline$\left(\mathrm{Fe}_{70} \mathrm{Ni}_{30}\right) \mathrm{Mo}_{4}$ & & & 5 & 1.67 & 300 & [32] \\
\hline $\mathrm{Fe}_{70} \mathrm{Zr}_{30}$ & & & 1.5 & 0.43 & 225 & {$[35]$} \\
\hline $\mathrm{Fe}_{2} \mathrm{MnSi}_{1-\mathrm{x}} \mathrm{Ge}_{\mathrm{x}}$ & $\begin{array}{l}\text { precursor step (homogenization } \\
\text { of composition) }\end{array}$ & $\begin{array}{l}\text { reduction of } \\
\text { annealing time }\end{array}$ & 5 & 1.6 & 270 & {$[25]$} \\
\hline $\mathrm{La}_{1-\mathrm{y}} \mathrm{RE}_{\mathrm{y}} \mathrm{Fe}_{11.4} \mathrm{Si}_{1.6}$ & & & 5 & 18 & 200 & {$[15]$} \\
\hline $\mathrm{LaFe}_{13-\mathrm{x}} \mathrm{Si}_{\mathrm{x}}$ & & & 2 & 24 & 200 & [16] \\
\hline $\mathrm{LaFe}_{11.57} \mathrm{Si}_{1.43} \mathrm{H}_{\delta}$ & final step & reactive milling & 2 & 18 & 346 & [18] \\
\hline $\mathrm{Fe}_{75} \mathrm{Nb}_{10} \mathrm{~B}_{15}$ & & $\begin{array}{l}\text { enhancement of } \\
\text { magnetism }\end{array}$ & 1.5 & 0.95 & 395 & [36] \\
\hline
\end{tabular}

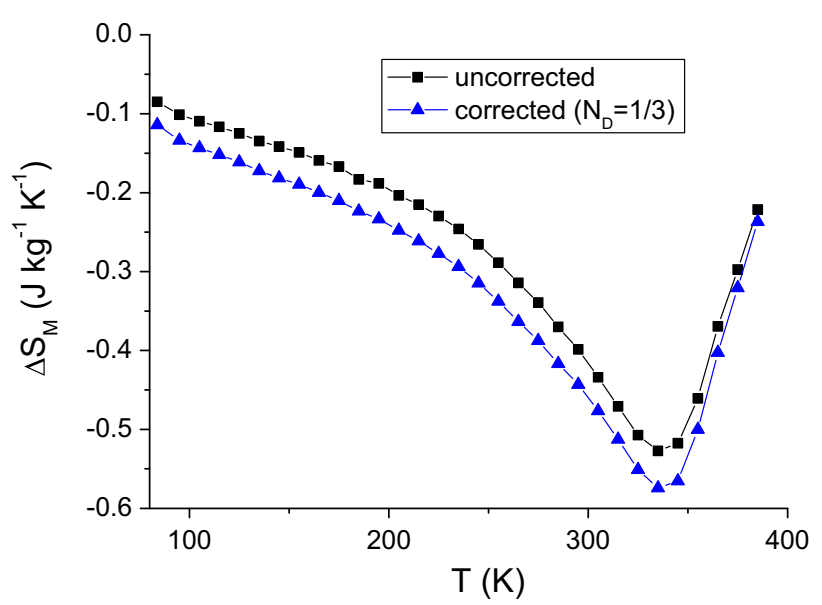

Fig. 1-Magnetic entropy change at $H=1 \mathrm{~T}$ with and without correcting the demagnetizing field for a ball-milled sample of $\mathrm{Fe}_{75} \mathrm{Nb}_{10} \mathrm{~B}_{15}$ amorphous alloy obtained by rapid quenching.

where $f$ is the packing fraction and $N_{\mathrm{D}}^{\text {pack }}$ is the demagnetizing factor corresponding to the shape of the package where the powders are enclosed.

Figure 1 shows the magnetic entropy change obtained with and without correcting the demagnetizing field (using $N_{\mathrm{D}}=1 / 3$ corresponding to loosely compacted spherical powder or to a spherical-like package of this powder independent of $f$ ). The largest effect of $N_{D}$ is at the Curie temperature but it remains below

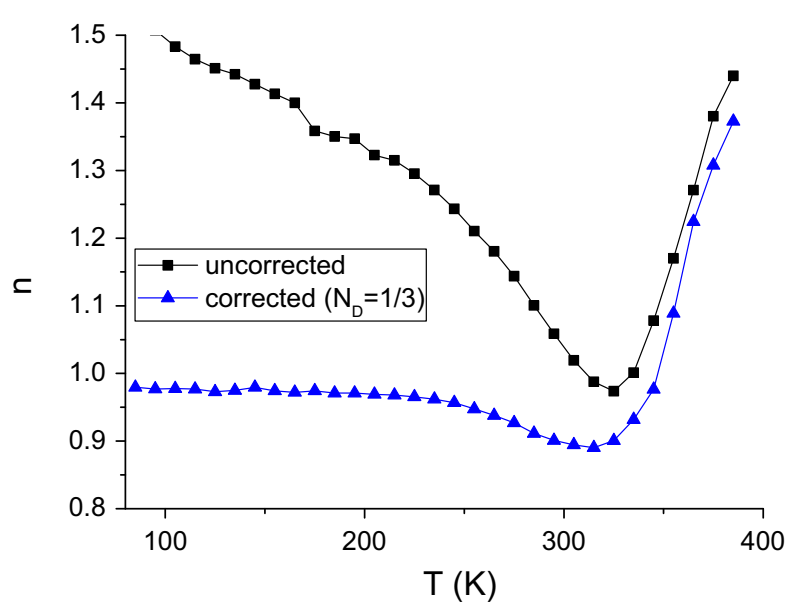

Fig. 2-Exponent $n$ of the field dependence of the magnetic entropy change at $H=1 \mathrm{~T}$ with and without correcting the demagnetizing field for a ball-milled sample of $\mathrm{Fe}_{75} \mathrm{Nb}_{10} \mathrm{~B}_{15}$ amorphous alloy obtained by rapid quenching.

$\sim 5$ pct. ${ }^{[37,41,43]}$ This allows us to conclude that neglecting demagnetizing field effects simply leads to a slight underestimation of the MCE. However, there is an important effect in the field dependence of the magnetic entropy change when demagnetizing field is not taken into account. This field dependence can be characterized by an exponent $n$ assuming a power law: ${ }^{[46,47]}$

$$
\left|\Delta S_{\mathrm{M}}\right|=a H^{n}
$$


In general $n$ depends on $H$ and $T$ but for single-phase systems and temperatures well below the Curie temperature $n=1$, while for temperatures well above the Curie temperature $n=2$. Moreover, for SOPT, $n$ at $T_{\mathrm{C}}$ is related to the critical exponents of the transition. ${ }^{[46]}$ Figure 2 shows the temperature dependence of the exponent $n$ for $H=1 \mathrm{~T}$ with and without correcting the demagnetizing field. Curves without correcting the demagnetizing field show $n>1$ values for $T<T_{\mathrm{C}}$, which increase as the applied field increases. Moreover, $n$ at $T_{\mathrm{C}}$ shows a field dependence unlike theoretical predictions. For $T>T_{\mathrm{C}}$, as expected, there is no effect of the demagnetizing field. After correcting the demagnetizing field, $n \leq 1$ below $T_{\mathrm{C}}$ and approaches a fieldindependent value of 1 as $T$ decreases. Moreover, at $T_{\mathrm{C}}$, field independence is recovered, in agreement with the theoretical predictions. Therefore, the correction of the demagnetizing factor is crucial in the discussion on the field dependence of the magnetic entropy change.

\section{EFFECT OF IMPURITIES}

The route to produce alloys by mechanical alloying can lead to the presence of impurity phases. ${ }^{[12]}$ When heterogeneous starting powders are used to produce a mechanically alloyed system, the different degree of integration of the elements or the different transformation degree of the phases imply the presence of inclusions (e.g., remnant supersaturated bcc-Fe crystallites in Fe-based amorphous phases). This is particularly important when very hard and brittle materials are used ${ }^{[12,48]}$ such as diamond ${ }^{[49]}$ boron, ${ }^{[50,51]}$ or germanium ${ }^{[52]}$ for which the inclusions remain even after very long milling times. In the case of $\mathrm{Ge}$ in Fe-based alloys, the Ge crystals are finally dissolved into the nanocrystalline supersaturated bcc matrix ${ }^{[52]}$ unlike for B inclusions, which remain even when the initial amount of the pure element is reduced. ${ }^{[50,51]}$ Figure 3 shows a TEM micrograph and the corresponding EDX maps and energy-filtered images describing the progressive integration of $\mathrm{Ge}$ atoms in $\mathrm{FeGeNb}$ alloys. Figure 4 shows a scanning electron microscopy image of $\mathrm{B}$ inclusions present in CoNbZrB alloys. This secondary electron image was obtained in a scanning electron microscope equipped with a focus ion beam (FIB) column. A cross section of the selected powder particle was polished using the $\mathrm{Ga}$ ion beam to form a smooth surface where the B inclusions are clearly observed as dark spots (regions of low interaction with electrons due to the low atomic number of B atoms).

Concerning MCE, the simplest approach for describing these multiphased samples is to consider noninteracting phases. In this case, the total entropy change is obtained as the weighted sum of the contributions of the main phase and the impurity phase.

$$
\left|\Delta S_{\mathrm{M}}\right|=(1-X) \Delta S_{\mathrm{M}}^{(\mathrm{main})}+X \Delta S_{\mathrm{M}}^{(\mathrm{imp})},
$$
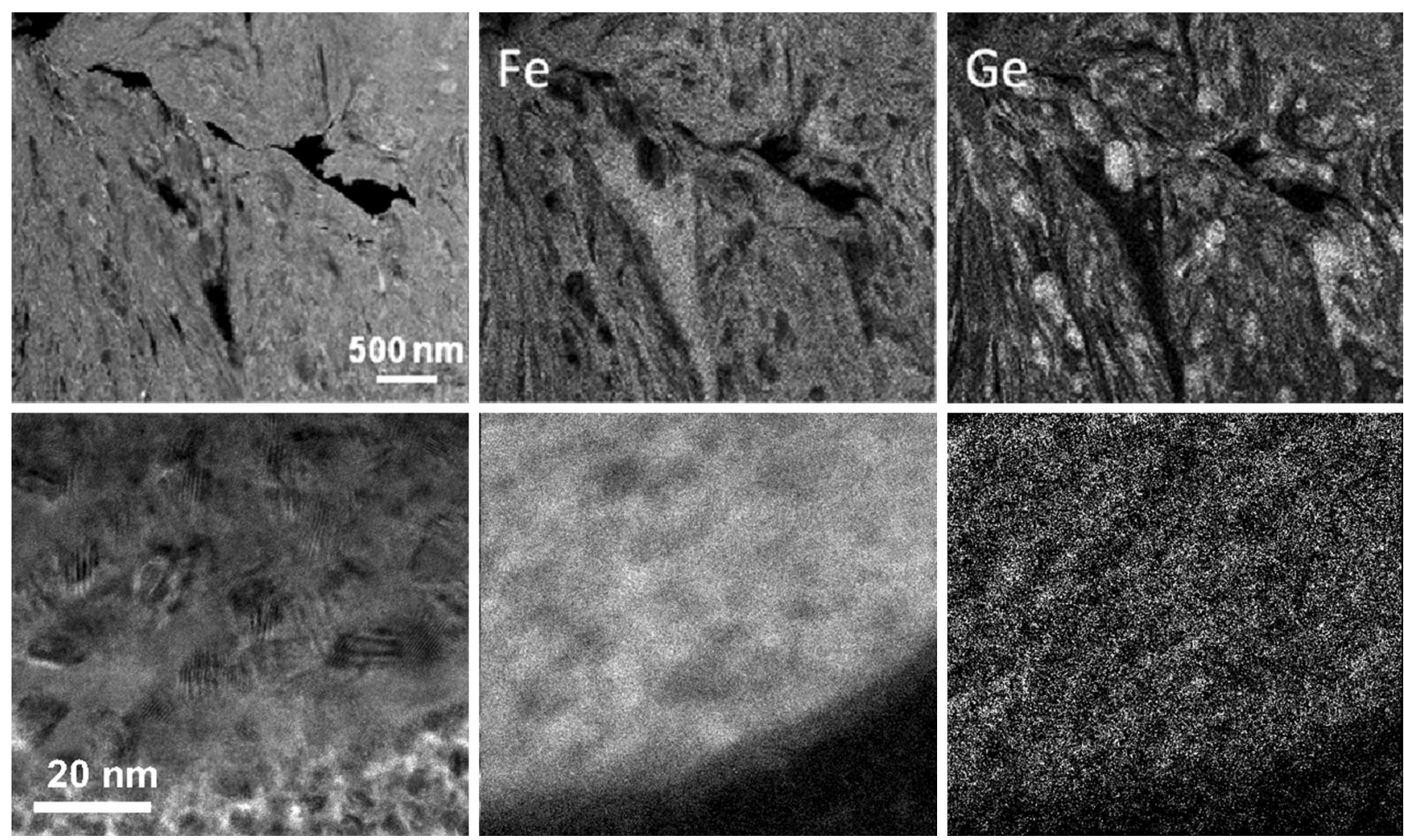

Fig. 3-Transmission electron microscopy (TEM) images of mechanically alloyed $\mathrm{Fe}_{75} \mathrm{Nb}_{5} \mathrm{Ge}_{20}$ system at 250 rpm. TEM samples prepared as described in Ref. [48] Upper row (from left to right): Annular dark field image and EDX maps for Fe and Ge elements, respectively, after $10 \mathrm{~h}$ of milling. Lower row (from left to right): TEM bright field image and energy-filtered TEM maps for Fe and Ge, respectively, after $150 \mathrm{~h}$ of milling. 


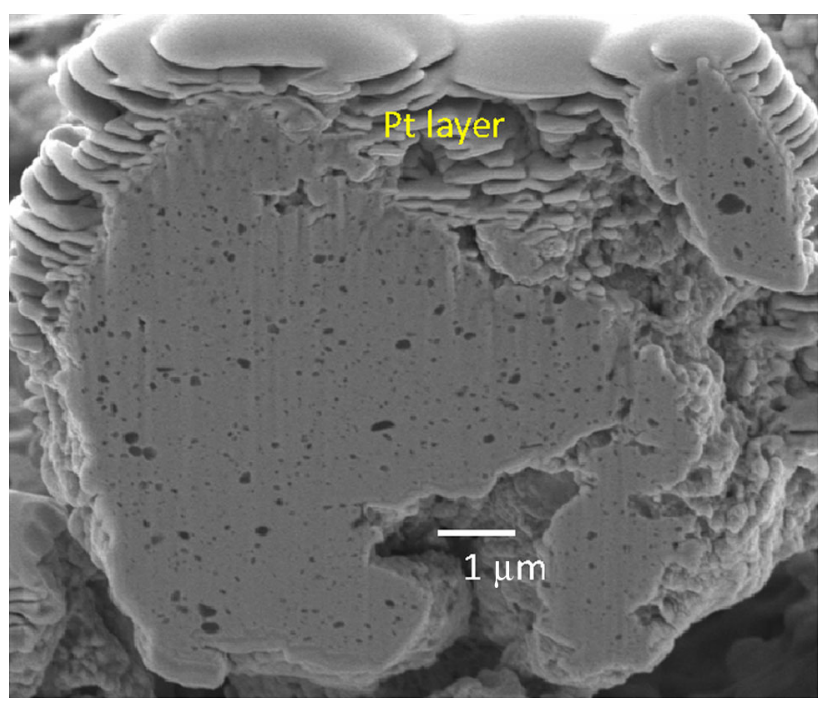

Fig. 4-Scanning electron microscopy (SEM) secondary electron image (acquired during FIB milling). Sample was polished in situ using gallium ion beam. Boron inclusions appear as dark spots. Layered structure surrounding the powder grain corresponds to the Pt deposited to protect the sample.

where $X$ is the fraction of impurities. Assuming a power law for the field dependence of each individual phase, Eq. [5] can be written as:

$$
\left|\Delta S_{\mathrm{M}}\right|=a_{\text {main }}(1-X) H^{n_{\text {main }}}+a_{\text {imp }} X H^{n_{\text {imp }}},
$$

where the indexes main and imp correspond to the main phase and the impurity phase, respectively. The prefactors $a_{\text {main }}$ and $a_{\text {imp }}$ correspond to the absolute value of the magnetic entropy change of each individual phase at $1 \mathrm{~T}$ and the exponents $n$ should be, in general, field dependent except for $T \ll T_{\mathrm{C}}, T \gg T_{\mathrm{C}}$, and $T=T_{\mathrm{C}}$ (for SOPT). ${ }^{[46]}$ However, when analyzing the data, a local experimental value of $n$ can be always obtained from Eq. [4] as the slope of the double logarithmic representation of $\left|\Delta S_{\mathrm{M}}\right|$ vs $H$.

$$
n=\frac{\mathrm{d} \ln \left(\left|\Delta S_{\mathrm{M}}\right|\right)}{\mathrm{d} \ln (H)}
$$

Using Eqs. [6] and [7] it is possible to obtain a general relation between the experimental value of $n$ and the individual values for the main and the impurity phases.

$$
n=\frac{a_{\text {main }} n_{\text {main }}(1-X) H^{n_{\text {main }}}+a_{\text {imp }} n_{\text {imp }} X H^{n_{\text {imp }}}}{\Delta S_{\mathrm{M}}}
$$

And using Eq. [4]

$$
n=\frac{n_{\text {main }}}{1+\frac{a_{\text {imp }}}{a_{\text {main }}} \frac{X}{(1-X)} H^{n_{\text {imp }}-n_{\text {main }}}}+\frac{n_{\text {imp }}}{1+\frac{a_{\text {main }}(1-X)}{a_{\text {imp }}} \frac{X}{X} H^{n_{\text {main }}-n_{\text {imp }}}}
$$

From expression [9] it is observed that as $X$ tends to zero, $n$ tends to $n_{\text {main }}$, as expected. It is worth mentioning that, although the temperature regime was valid for both $n_{\text {main }}$ and $n_{\text {imp }}$ to be field independent when the

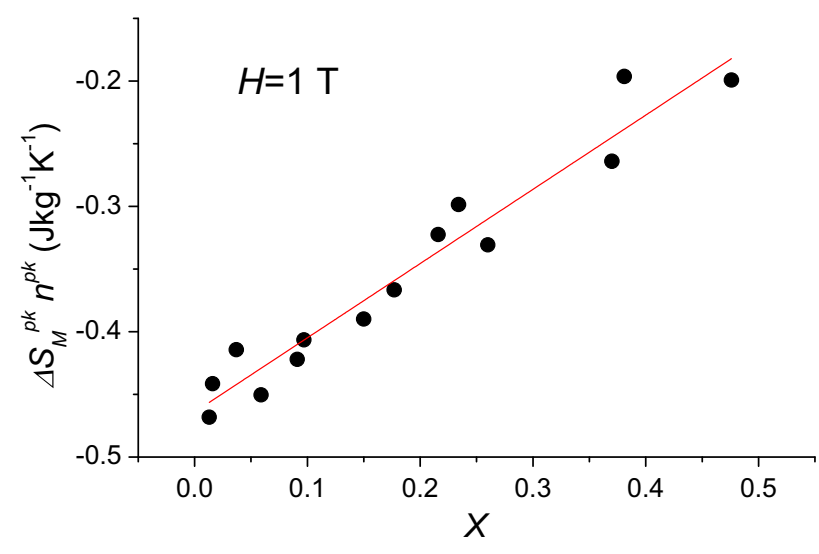

Fig. 5-Linear plot of the product of the magnetic entropy change and the field exponent $v s$ fraction of impurity phase as predicted by expression [10] and applied to mechanically alloyed $\mathrm{Fe}_{75} \mathrm{Nb}_{10} \mathrm{~B}_{15}$ amorphous system with $\alpha$-Fe crystallites.

phases are isolated, $n$ would be field dependent unless $n_{\text {main }}=n_{\text {imp. }}$. Therefore, in order to obtain the exponent value of the main phase Eq. [8] can be rewritten as:

$$
\begin{aligned}
& n\left|\Delta S_{\mathrm{M}}\right|=a_{\text {main }} n_{\text {main }} H^{n_{\text {main }}}+\left(a_{\mathrm{imp}} n_{\mathrm{imp}} H^{n_{\mathrm{mpp}}}\right. \\
& \left.-a_{\text {main }} n_{\text {main }} H^{n_{\text {main }}}\right) X=y_{0}+m X
\end{aligned}
$$

Therefore, for constant magnetic field and temperature (to ensure a constant value of the prefactors $a_{\text {main }}$ and $a_{\mathrm{imp}}$ ), the product $n\left|\Delta S_{\mathrm{M}}\right|$ linearly increases as the volume fraction of impurities increases. A linear fitting of $n\left|\Delta S_{\mathrm{M}}\right|(X)$ allows us to obtain both parameters, the intercept $y_{0}$ and the slope $m$. The intercept $y_{0}=a_{\text {main }} n_{\text {main }} H^{\text {main }}$ is thus independent of $X$ and the value of interest, $n_{\text {main }}$, can be obtained from the slope of the $\ln \left(y_{0}\right) v s \ln (H)$ :

$$
\ln \left(y_{0}\right)=\ln \left(a_{\text {main }} n_{\text {main }}\right)+n_{\text {main }} \ln (H)
$$

As this analysis uses the intercept $y_{0}$, the possible ambiguities in the determination of $X$ is overcome. In fact, the measurements of the fraction of impurities is not simple and each technique would supply a particular interpretation of this parameter (coherent volume from diffraction techniques, magnetic fractions, etc.). In any case, a proportional relation between the different fractions is a reasonable and widely used assumption and does not affect our analysis. Although our analysis is extended to any value of $X$, it is required that the MCE responses of each phase do not depend on $X$, i.e., that they are non-interacting.

The previous analysis was applied to the study of $\mathrm{FeNbB}$ amorphous alloys with $\alpha-\mathrm{Fe}$ as the impurity phase and produced by mechanical alloying. ${ }^{[41]}$ Figure 5 shows the linear relation predicted by Eq. [10] and Figure 6 was built using the slopes obtained at different fields. From them, an exponent $n=0.757 \pm 0.012$ is estimated for a pure amorphous phase, in agreement with those corresponding to pure amorphous systems obtained by rapid quenching. ${ }^{[53]}$ 


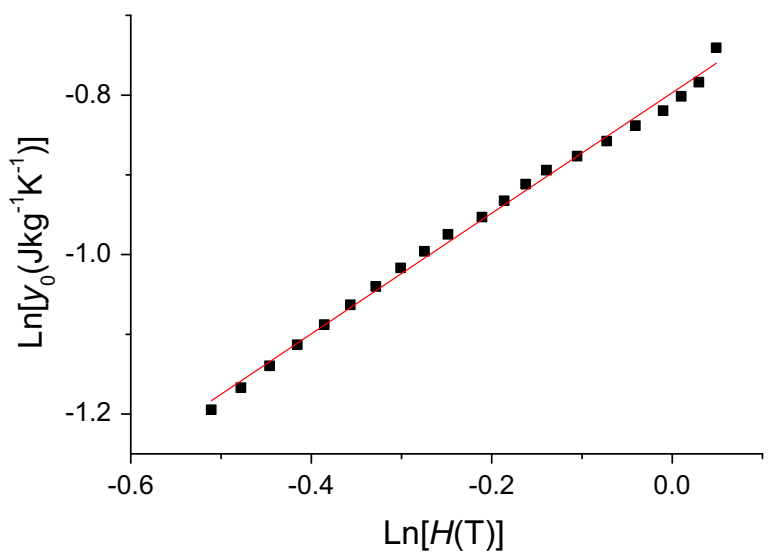

Fig. 6-Linear plot of the logarithm of the intercept values of $n \Delta S_{\mathrm{M}}$ product $v s X$ as a function of the logarithm of magnetic field as predicted by expression [11] and applied to $\mathrm{Fe}_{75} \mathrm{Nb}_{10} \mathrm{~B}_{15}$ amorphous alloy with $\alpha$-Fe crystallites.

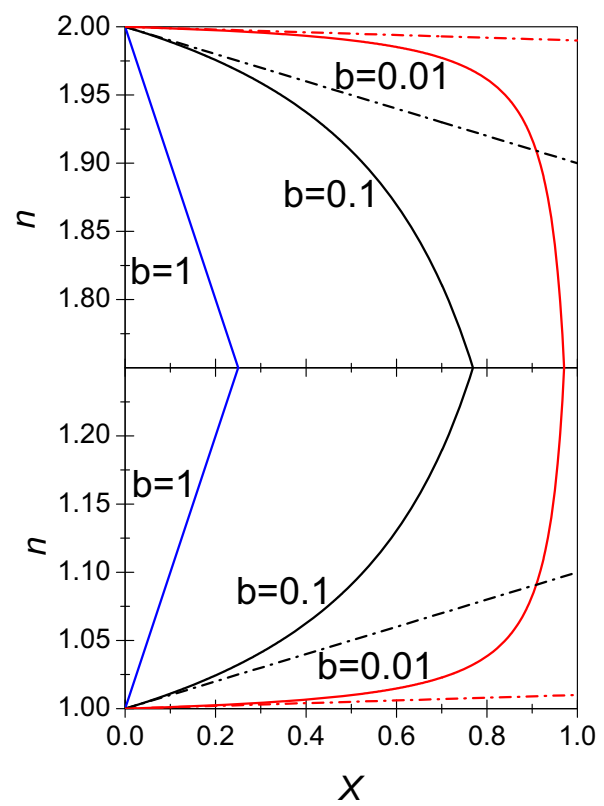

Fig. 7-Theoretical values of $n$ as a function of the impurity fraction, $X$, and for different values of $b(H)$. Upper panel: well above $T_{\mathrm{C}}$ of the main phase $\left(n_{\text {main }}=2\right)$ and ferromagnetic impurities with a high Curie transition $\left(n_{\mathrm{imp}}=1\right)$. Lower panel: well below $T_{\mathrm{C}}$ of the main phase $\left(n_{\text {main }}=1\right)$ and paramagnetic impurities with low Curie temperature $\left(n_{\mathrm{imp}}=2\right)$.

Equation [9] can be simplified for very low values of $X$ as it is done in Reference 38 :

$$
n=n_{\text {main }}+\left(n_{\text {imp }}-n_{\text {main }}\right) b(H) X,
$$

where

$$
b(H)=\frac{a_{\mathrm{imp}}}{a_{\mathrm{main}}} H^{n_{\mathrm{imp}}-n_{\text {main }}}
$$

Equation [12] would allow us to obtain $n_{\text {main }}$ in a more straightforward way than from [11] but limiting the analysis to low values of $X$. Figure 7 shows the theoretical values of $n$ as a function of the impurity fraction and for different values of $b(H)$ for two cases:

a) a sample with paramagnetic impurities measured at a temperature well below $T_{\mathrm{C}}$ of the main phase $\left(n_{\text {main }}=1\right.$ and $\left.n_{\text {imp }}=2\right)$ and

b) a sample with ferromagnetic impurities with a high Curie transition well above $T_{\mathrm{C}}$ of the main phase $\left(n_{\text {main }}=2\right.$ and $\left.n_{\text {imp }}=1\right)$.

A typical example of the latter type of impurities are remnant $\alpha-\mathrm{Fe}$ crystallites, where Curie temperature is well above room temperature. The approximation for low values of $X$ (Eq. [12]) are also plotted to show its validity limit. It can be concluded that both demagnetizing factor and paramagnetic impurities effect can lead to exponents above 1 for ferromagnetic samples.

\section{CURIE TEMPERATURE DISTRIBUTIONS}

As-milled amorphous samples can exhibit some heterogeneity, such as inclusions, leading to a broader compositional distribution compared to that of amorphous phases obtained by rapid quenching. In the case of crystalline materials, ball milling normally leads to very small crystal size and thus surface effects (e.g., atom magnetic moment disordering) can also lead to a smoother magnetic transition. These features can explain the observed general decrease in the absolute value of the maximum magnetic entropy change as well as the broadening of the MCE peak. Concerning the field dependence of $\Delta S_{\mathrm{M}}$, the presence of a Curie temperature distribution does not affect the behavior far away from the transition but leads to a smearing of the $n(T)$ curve and, moreover, the values achieved at the (average) Curie temperature are not consistent with the theoretical predictions but higher. ${ }^{[34]}$

In order to obtain a deeper understanding of the effect of the presence of a $T_{\mathrm{C}}$ distribution on the MCE response, a non-interacting approach can be assumed and the total $\Delta S_{\mathrm{M}}$ can be obtained as a weighted sum using a Gaussian distribution of the individual contributions:

$$
\Delta S_{\mathrm{M}}^{\mathrm{total}}(T)=\int_{\left\langle T_{\mathrm{C}}\right\rangle-\Delta}^{\left\langle T_{\mathrm{C}}\right\rangle+\Delta} \frac{\mathrm{d} \Delta S_{\mathrm{M}}\left(T, T_{\mathrm{C}}^{*}\right)}{\mathrm{d} T_{\mathrm{C}}^{*}} G\left(T_{\mathrm{C}}^{*}, \sigma\right) \mathrm{d} T_{\mathrm{C}}^{*} .
$$

where $G\left(<T_{\mathrm{C}}>, \sigma\right)$ can be assumed as a Gaussian distribution centered at $\left\langle T_{\mathrm{C}}\right\rangle$ and with a standard deviation $\sigma$, and $<T_{\mathrm{C}}>-\Delta$ to $<T_{\mathrm{C}}>+\Delta$ is the $T_{\mathrm{C}}$ range for which a significant contribution exists (e.g., if $\Delta=4 \sigma$, only contributions below 0.01 pct would be neglected). Other approaches to this problem have been afforded by different authors using a rectangular distribution to fit deviations found in $\mathrm{Gd}^{[54]}$ and using mean field models ${ }^{[55,56]}$ and Bean-Rodbell model. ${ }^{[57]}$

Theoretical calculations were performed to explain the different behavior observed between rapid quenching and mechanically alloyed $\mathrm{Co}_{62} \mathrm{Nb}_{6} \mathrm{Zr}_{2} \mathrm{~B}_{30}$ amorphous samples. In order to do so, expression [14] was simplified to a summatory of discrete $\Delta S_{\mathrm{M}}\left(T, T_{\mathrm{C}}\right)$ 


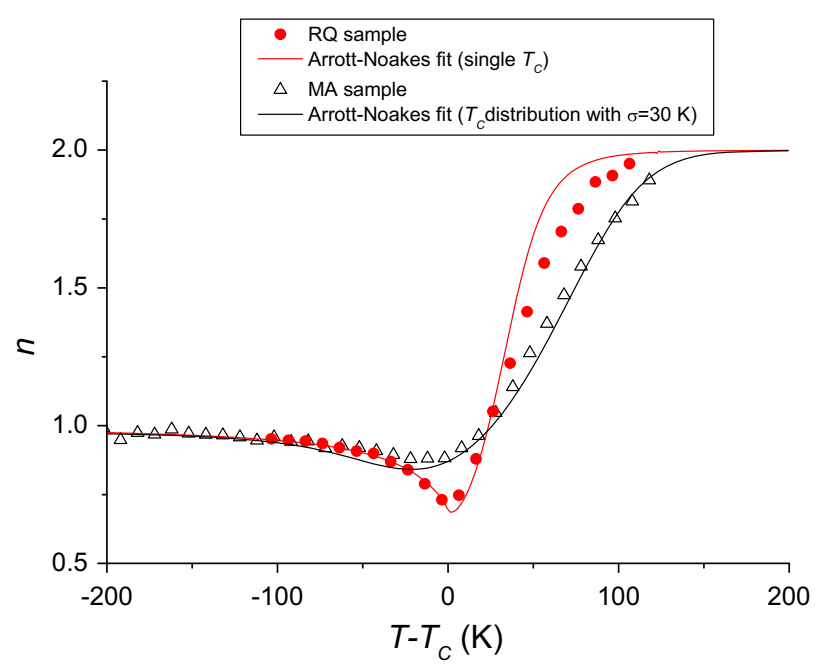

Fig. 8-Experimental and simulated curves of the field exponent $n$ for a rapidly quenched (RQ) and a mechanically alloyed (MA) sample of $\mathrm{Co}_{62} \mathrm{Nb}_{6} \mathrm{Zr}_{2} \mathrm{~B}_{30}$ composition. Simulated curves were generated with Arrott-Noakes equation of state using a single $T_{\mathrm{C}}$ for RQ sample and a Gaussian distribution of $T_{\mathrm{C}} \mathrm{S}$ with standard deviation $\sigma=30 \mathrm{~K}$ for the MA sample.

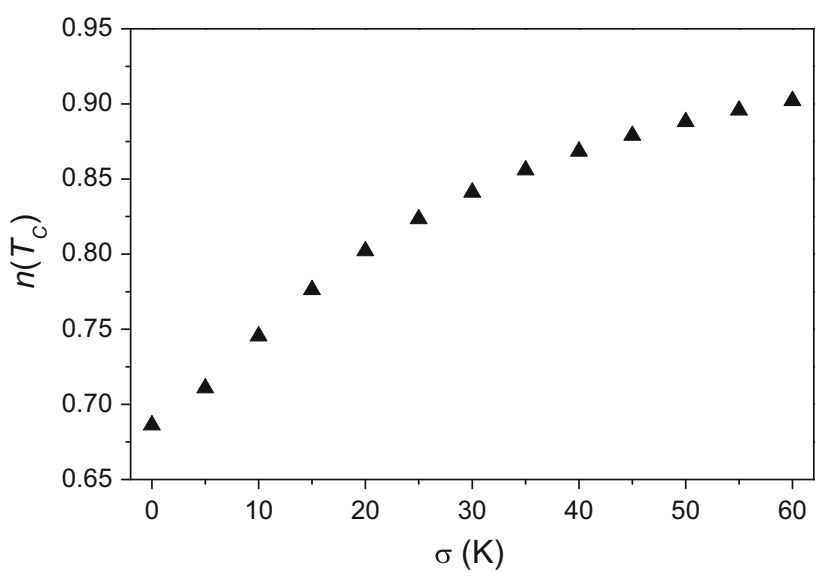

Fig. 9-Dependence of the field exponent $n$ on the standard deviation of the Gaussian distribution of $T_{\mathrm{C}} \mathrm{s}$.

responses weighed using a Gaussian distribution of $T_{\mathrm{C}}$ to describe the mechanically alloyed sample: $:^{[43]}$

$$
\Delta S_{\mathrm{M}}^{\text {total }}(T)=C \sum_{\left\langle T_{\mathrm{C}}\right\rangle-\Delta}^{\left\langle T_{\mathrm{C}}\right\rangle+\Delta} \Delta S_{\mathrm{M}}\left(T, T_{\mathrm{C}}^{*}\right) \exp \left[-\frac{\left(\left\langle T_{\mathrm{C}}\right\rangle-T_{\mathrm{C}}^{*}\right)^{2}}{2 \sigma^{2}}\right],
$$

where $C$ is a normalization constant. The values of each discrete $\Delta S_{\mathrm{M}}$ were generated using the Arrott-Noakes equation of state, ${ }^{[58]}$ using the parameters of a rapidly quenched amorphous alloy with the same composition (critical exponents determined from Kouvel-Fisher method $^{[59]}$ ). From these curves the exponent $n$ was obtained as a function of temperature and of the standard deviation of the distribution, $n(T, \sigma)$. Figure 8 shows a good agreement between the experimental and simulated $n(T)$ curves. As a general characteristic, $n(T)$ curves become smeared as $\sigma$ increases, increasing the value of $n$ at $T_{\mathrm{C}}$ and shifting the temperature ranges for field-independent $n \sim 1$ and $\sim 2$ to higher $\left|T-T_{\mathrm{C}}\right|$ values. Figure 9 shows the dependence of $n$ on $\sigma$ at the peak temperature showing that a distribution of Curie temperatures is a third factor that can lead to a $n\left(T_{\mathrm{C}}\right)$ value larger than the one theoretically predicted as a function of the critical exponents.

\section{CONCLUSIONS}

Ball milling has been used in different ways to produce systems with interesting magnetocaloric properties with very different compositions: as a one-step production from pure elements (mechanical alloying) to induce the formation of metastable phases, including amorphous alloys; as a procedure to enhance the atomic scale mixing to diminish the annealing time to produce certain intermetallics; or as reactive milling to enhance solid-gas reactions.

Regardless of the composition and character of the magnetic transition, there are several common aspects to all ball-milled powders which should be considered in the analysis of MCE data, particularly affecting the field dependence of the MCE response:

1. Demagnetizing field effect: As powder particles cannot be aligned with respect to the applied field direction to exhibit a zero demagnetizing factor, this effect is always present, being $N_{\mathrm{D}} \sim 1 / 3$ depending on the shape of the packing and the packing fraction of powders in the measured sample. This effect leads to higher values of the field exponent $n$ than the actual ones except above $T_{\mathrm{C}}$. Moreover, artificial field dependence of $n$ appears well below $T_{\mathrm{C}}$ and at $T_{\mathrm{C}}$, unlike theoretical predictions.

2. Presence of impurities can also lead to an artificial field dependence of $n$. Unlike demagnetizing field effect, the presence of ferromagnetic impurities leads to a decrease in $n$ values above $T_{\mathrm{C}}$. The relation between the experimental value and that of the main phase can be simplified to a linear one only for very low fractions of impurities. In the general case, the dependence on the impurity fraction is needed and the exponent $n$ of the main phase can be extracted from the field dependence of the intercept of the linear fitting of $n\left|\Delta S_{\mathrm{M}}\right| v s X$.

3 . Finally, the presence of Curie temperature distributions (due to strains or inhomogeneities) does not affect $n$ values far away from the transition. However, the $n(T)$ curve is smeared and the minimum value of $n$ increases, departing from the theoretically predicted value, which was related to the critical exponents.

\section{ACKNOWLEDGMENTS}

This work was supported by the Spanish Ministry of Science and Innovation and EU FEDER (Project MAT2013-45165-P), the PAI of the Regional Govern- 
ment of Andalucía (Project P10-FQM-6462). The research leading to TEM results has received funding from the European Union Seventh Framework Programme under Grant Agreement 312483-ESTEEM2 (Integrated Infrastructure Initiative-I3).

\section{REFERENCES}

1. V.K. Pecharsky and K.A. Gschneidner: Phys. Rev. Lett., 1997, vol. 78, pp. 4494-97.

2. W.F. Giauque and D.P. MacDougall: Phys. Rev., 1933, vol. 43, p. 768.

3. A.O. Pecharsky, K.A. Gschneidner, Jr, V.K. Pecharsky, and C.E. Schindler: J. All. Compds., 2002, vol. 338, pp. 126-35.

4. A. Fujita, S. Fujieda, Y. Hasegawa, and K. Fukamichi: Phys. Rev. $B, 2003$, vol. 67, p. 104416 .

5. A. Planes, L. Mañosa, X. Moya, T. Krenke, M. Acet, and E.F. Wassermann: J. Mag. Mag. Mat., 2007, vol. 310, pp. 2767-69.

6. H. Wada and Y. Tanabe: Appl. Phys. Lett., 2001, vol. 79, p. 3302.

7. V. Franco, J.S. Blázquez, B. Ingale, and A. Conde: Ann. Rev. Mater. Res., 2012, vol. 42, pp. 305-42.

8. S.Y. Dan'kov, A.M. Tishin, V.K. Pecharsky, and K.A. Gschneidner, Jr.: Phys. Rev. B, 1998, vol. 57, pp. 3478-90.

9. V. Franco and A. Conde: Scripta Mater., 2012, vol. 67, pp. 594-99.

10. W.H. Wang: Adv. Mater., 2009, vol. 21, pp. 4524-44.

11. H. Maeda, M. Sato, and M. Uehara: J. Jpn. Inst. Met., 1983, vol. 47, pp. 688-91.

12. C. Suryanarayana: Prog. Mater Sci., 2001, vol. 46, pp. 1-184.

13. T.B. Zhang, V. Provenzano, Y.G. Chen, and R.D. Shull: Sol. State Comm., 2008, vol. 147, pp. 107-10.

14. D.M. Rajkumar, M.M. Raja, R. Gopalan, and V. Chandrasekaran: J. Mag. Mag. Mater., 2008, vol. 320, pp. 1479-84.

15. E.C. Passamani, A.Y. Takeuchi, A.L. Alves, A.S. Demuner, E. Favre-Nicolin, C. Larica, J.R. Proveti, and A.M. Gomes: J. Appl. Phys., 2007, vol. 102, p. 093906.

16. M. Phejar, V. Paul-Boncour, and L. Bessais: Intermetallics, 2010, vol. 18, pp. 2301-07.

17. K. Mandal, O. Gutfleisch, A. Yan, A. Handstein, and K.H. Muller: J. Mag. Mag. Mater., 2005, vol. 290, pp. 673-75.

18. K. Mandal, D. Pal, O. Gutfleisch, P. Kerschl, and K.H. Muller: $J$. Appl. Phys., 2007, vol. 102, p. 053906.

19. P. Alvarez-Alonso, J.L. Sánchez Llamazares, C.F. SánchezValdes, G.J. Cuello, V. Franco, P. Gorria, and J.A. Blanco: J. Appl. Phys., 2014, vol. 115, p. 17A929.

20. P. Gorria, P. Álvarez, J.S. Marcos, J.L. Sánchez Llamazares, M.J Pérez, and J.A. Blanco: Acta Mater., 2009, vol. 57, pp. 1724-33.

21. A. Biswas, S. Chandra, S. Stefanovski, J.S. Blázquez, J.J. Ipus, A. Conde, M.H. Phan, V. Franco, G.S. Nolas, and H. Shrikanth: J. Appl. Phys., 2015, vol. 117, p. 033903.

22. B. Chevalier, J.L. Bobet, J.S. Marcos, J.R. Fernandez, and J.C.G. Sal: Appl. Phys. A-Mater. Sci. \& Proc., 2005, vol. 80, pp. 601-06.

23. Y.V.B. de Santanna, M.A.C. de Melo, I.A. Santos, A.A. Coelho, S. Gama, and L.F. Cótica: Sol. State Comm., 2008, vol. 148, pp. $289-92$.

24. A.G. Varzaneh, P. Kameli, F. Karimzadeh, B. Aslibeiki, G. Varvaro, and H. Salamati: J. All. Compds., 2014, vol. 598, pp. 6-10.

25. L. Zhang, E. Bruck, O. Tegus, K.H.J. Buschow, and F.R. de Boer: Physica B: Condens. Matter., 2003, vol. 328, pp. 295-301.

26. W.B. Cui, W. Liu, X.H. Liu, S. Guo, Z. Han, X.G. Zhao, and Z.D. Zhang: J. All. Compds., 2009, vol. 479, pp. 189-92.

27. W.B. Cui, W. Liu, X.H. Liu, S. Guo, Z. Han, X.G. Zhao, and Z.D. Zhang: Mater. Lett., 2009, vol. 63, pp. 595-97.
28. N.K. Sun, F. Liu, Y.B. Gao, Z.Q. Cai, B.S. Du, S.N. Xu, and P.Z. Si: Appl. Phys. Lett., 2012, vol. 100, p. 112407.

29. N.K. Sun, S.N. Xu, Y.B. Gao, T.B. Ji, and Y.B. Li: Physica B: Condens. Matter., 2011, vol. 406, pp. 2731-33.

30. J.J. Ipus, H. Ucar, and M.E. McHenry: IEEE Trans. Mag., 2011, vol. 47, pp. 2494-97.

31. H. Ucar, J.J. Ipus, D.E. Laughlin, and M.E. McHenry: J. Appl. Phys., 2013, vol. 113, p. 17A918.

32. H. Ucar, M. Craven, D.E. Laughlin, and M.E. McHenry: J. Elect. Mater., 2014, vol. 43, pp. 137-41.

33. J.J. Ipus, J.S. Blázquez, V. Franco, A. Conde, and L.F. Kiss: $J$. Appl. Phys., 2009, vol. 105, p. 123922.

34. J.J. Ipus, J.S. Blázquez, V. Franco, and A. Conde: J. All. Compds., 2010, vol. 496, pp. 7-12.

35. J.S. Blázquez, V. Franco, and A. Conde: Intermetallics, 2012, vol. 26 , pp. 52-6.

36. J.J. Ipus, J.S. Blázquez, V. Franco, M. Stoica, and A. Conde: $J$. Appl. Phys., 2014, vol. 115, p. 17B518.

37. L.M. Moreno, J.S. Blázquez, J.J. Ipus, J.M. Borrego, V. Franco, and A. Conde: J. Appl. Phys., 2014, vol. 115, p. 17A302.

38. R. Caballero-Flores, V. Franco, A. Conde, and L.F. Kiss: J. Appl. Phys., 2009, vol. 105, p. 07A919.

39. G. Diguet, G. Lin, and J. Chen: J. Mag. Mag. Mat., 2013, vol. 326, pp. 103-07.

40. B. Schwarz, N. Mattern, J.D. Moore, K.P. Skokov, O. Gutfleisch, and J. Eckert: J. Mag. Mag. Mat., 2011, vol. 323, pp. 1782-86.

41. J.J. Ipus, L.M. Moreno-Ramírez, J.S. Blázquez, V. Franco, and A. Conde: Appl. Phys. Lett., 2014, vol. 105, p. 172405.

42. P. Alvarez-Alonso, P. Gorria, J.S. Marcos, J.L. Sánchez Llamazares, and J.A. Blanco: J. Phys.: Condens. Matter, 2013, vol. 25 , p. 496010

43. L.M. Moreno-Ramírez, J.J. Ipus, V. Franco, J.S. Blázquez, and A. Conde: J. All. Compds., 2015, vol. 622, pp. 606-09.

44. C. Romero-Muñiz, J.J. Ipus, J.S. Blázquez, V. Franco, and A. Conde: Appl. Phys. Lett., 2014, vol. 104, p. 252405.

45. J.M.D. Coey: Magnetism and Magnetic Materials, Cambridge University Press, New York, NY, 2010, p. 39.

46. V. Franco, J.S. Blázquez, and A. Conde: Appl. Phys. Lett., 2006, vol. 89 , p. 222512

47. V. Franco, A. Conde, J.M. Romero-Enrique, and J.S. Blázquez: $J$. Phys.: Condens. Matter, 2008, vol. 20, p. 285207.

48. J.S. Blázquez, J.J. Ipus, S. Lozano-Pérez, and A. Conde: JOM, 2013, vol. 65 , pp. $870-82$

49. D.J. Woo, B. Sneed, F. Peerally, F.C. Heer, L.N. Brewer, J.P. Hooper, and S. Osswald: Carbon, 2013, vol. 63, pp. 404-15.

50. J.J. Ipus, J.S. Blázquez, V. Franco, S. Lozano-Pérez, and A. Conde: J. All. Compds., 2013, vol. 553, pp. 119-24.

51. L.M. Moreno, J.S. Blázquez, J.J. Ipus, and A. Conde: J. All. Compds., 2014, vol. 585, pp. 485-90.

52. J.J. Ipus, J.S. Blázquez, S. Lozano-Pérez, and A. Conde: J. All. Compds., 2010, vol. 505, pp. 86-90.

53. V. Franco, J.S. Blázquez, M. Millán, J.M. Borrego, C.F. Conde, and A. Conde: J. Appl. Phys., 2007, vol. 101, p. 09C503.

54. J. Lyubina, M.D. Kuz'min, K. Nenkov, O. Gutfleisch, M. Richter, D.L. Schlagel, T.A. Lograsso, and K.A. Gschneidner, Jr.: Phys. Rev. B, 2011, vol. 83, p. 012403.

55. A.Y. Romanov and V.P. Silin: Met. Metalloved., 1997, vol. 83, pp. 5-11.

56. C.R.H. Bahl, R. Bjork, A. Smith, and K.K. Nielsen: J. Mag. Mag. Mat., 2012, vol. 324, pp. 564-68.

57. J.S. Amaral and V.S. Amaral: Phys. Stat. Sol. A, 2014, vol. 211, pp. $971-74$.

58. A. Arrott and J.E. Noakes: Phys. Rev. Lett., 1967, vol. 19, pp. $786-89$.

59. J.S. Kouvel and M.E. Fisher: Phys. Rev., 1964, vol. 136, p. A1626. 